\title{
18. Über das Vorkommen einer Trauertanne auf dem Berge Tarebora in Centraljapan.
}

\author{
Von Manabu MrYoshI, M.I.A. \\ (Comm. Feb. 13, 1939.)
}

Dass die Trauer- oder Hängetannen in Europa wild vorkommen, ist lange bekannt. ${ }^{1)}$ Dagegen giebt es meines Wissens bisher keinen Bericht über derartig wildwachsende Tannen in Japan.

Der hier mitgeteilte Fall ist interessant, da diese Anomalie gerade auf einem Berge gefunden wurde, wo menschliche Einflüsse ausgeschlossen sind.2)

Der Fundort des betreffenden Baumes, den ich im Frühjahr 1937 in Begleitung des Herrn Fukaya, Besitzer dieses Bergwaldes, besichtigte, befindet sich am steilen Abhange des Tareboraberges, Gifu Präfektur. Der Baum erhebt sich in einem Mischwald. Seine sämtlichen, aus gegabelten Stämmen hervortretenden Äste neigen sich abwärts. Die Länge der hängenden Äste ist ca $3 \mathrm{~m}$. Der Umfang an der Stammbasis ca $1,45 \mathrm{~m}^{3)}$ Die dadurch resultierte lange schmale Gestalt unseres Baumes lässt sich, von weitem betrachtet, kaum als eine Tanne erkennen.

Gegenwärtig existiert, wie oben erwähnt, nur ein einziges lebendes Exemplar der Trauertanne in Tarebora. ${ }^{4)}$

Herr Fukaya teilte mir mündlich mit, dass früher nahe bei dieser Trauertanne eine ähnliche gestanden hat. Diese Stelle untersuchte ich sofort, fand aber nur einen faulenden Stammrest jenes Tannenbaumes.

$\mathrm{Da}$ die Trauerform, wie erwähnt, schon zweimal bei Tannen in Tarebora aufgetreten ist, so liegt der Gedanke nahe, dass sich mit der Zeit diese Anomalie wiederholen kann.

Vom biologischen Standpunkt aus ist die Trauertanne deshalb als ein Beispiel der unzweckmässigen Mutation anzusehen, weil eine derartig gestaltete Tanne, welche so im Gegensatz zu normalen mit wagerechten Ästen steht, durch nebenstehende Bäume im Waldesinnern leicht unterdrückt werden kann.

Abies firma S. et Z. var. pendula Miyos.

Arbor mediocris, ramis penduli.

Hab. Japonia media. Spontanea in montis Tarebora.

Nom. jap. Sidare Momi.

1) Penzig, Pflanzenteratologie. 2. Aufl. III. Bd. 1922, S. 506.

2) Betreffs dieser Tranuertanne bekam ich zuerst Mitteilung von Herrn H. Makino in Tuketi.

3) Eine ähnliche Trauertanne (Abies alba var. virgata Casp.) fand Caspary in Böhmen 1877, mit $22 \mathrm{~m}$ Stammhöhe und 4-5 m langen Ästen. Beissner, Handbuch der Nadelholzkunde. 3. Aufl. 1930, S. 113.

4) Diese Trauertanne wurde bereits als Naturdenkmal gesetzlich geschützt. 